Ann. Biol. anim. Bioch. Biophys., 1979, 19 (4 B), 1239.

\title{
Discussion note on the paper of S. S. Wachtel on « H-Y antigen in the functional female »
}

par U. MÜLLER, U. WOLF

Instifuf für Humangenetik der Universifät Freiburg i. Br.

D-7800 Freiburg, Albertstr. 11, F. R. G.

The results obtained in the pedigree presented can be interpreted by supposing an autosomal location of the $\mathrm{H}-\mathrm{Y}$ gene as well. In this case, a leaky mutation has to be assumed, allowing for residual expression of the $\mathrm{H}$ - $\mathrm{Y}$ gene. This type of mutation is compatible with an autosomal recessive mode of inheritance. The residual expression could be based on a mutation affecting the operator region of the $\mathrm{H}-\mathrm{Y}$ structural gene, resulting in incomplete repression. Therefore, the amount of $\mathrm{H}-\mathrm{Y}_{\text {. antigen in female }}$ heterozygous individuals may not reach the threshold necessary to convert the indifferent gonad into a testis (there is evidence for a threshold effect of $\mathrm{H}-\mathrm{Y}$ antigen in $X O / X Y$ mosaics, most of them being of female phenotype, with a few intermediates or even males). Thus, the heterozygous mothers of these $X X$-males are $H-Y$ positive (reduced rate or so, depending on the sensitivity of the method), and may even have some ovotestis which must be compatible with fertility. The same mutation must exist in the fathers, of course without affecting them. In both assumptions (multiple $\mathrm{H}-\mathrm{Y}$ genes on the $Y$-chromosome combined with a translocation, or a single autosomal gene) both parents must be affected by the same mutation, and in this case, they would have to be related to each other. Thus, the problem in this paper is whether or not the parents of the $X X$ males are related. The problem is the same in both assumptions, and therefore the possibility of a leaky mutation is not ruled out.

4th Workshop on « Development and maturation of the reproductive organs and functions 》 Luynes, France, octobre 1978. 